\title{
Comparing push and pull measures for PV and wind in Europe
}

\author{
Ruben Laleman ${ }^{1 *}$, Johan Albrecht ${ }^{1}$ \\ 1 Ghent University, Faculty of Economics and Business administration, Ghent, Belgium \\ *corresponding author. Tel: +32 92644209, E-mail: ruben.laleman@ugent.be
}

\begin{abstract}
Successful technological innovation frameworks are based on synergistic packages of technologypush and demand-pull measures. As the massive deployment of premature renewable energy technologies risks becoming very expensive, the debate on the optimal trajectory of renewable technologies should explicitly consider the balance between deployment incentives and R\&D efforts.
\end{abstract}

This paper explores this balance regarding wind and PV technology support in Europe. Based on rather conservative estimates, we calculate future deployment costs and compare these figures to the current public investments in PV and wind R\&D. We find that, today, for each Euro spent on R\&D to develop future technologies, 35 to 41 Euros are spent on the deployment of existing technologies. Furthermore, private PV and wind technology companies tend to underinvest in R\&D for various reasons. In an alternative scenario, we assess the optimal R\&D efforts for the PV and wind sectors based on a 7\% R\&D-to-sales benchmark that is typical for engineering sectors. If public R\&D efforts would increase according to this benchmark, and hence compensate for the private underinvestments in R\&D, pull/push ratios between 6 and 8 could be achieved. This leads us to conclude that the current balance between deployment and R\&D is far from optimal.

Keywords: Wind energy, PV-systems, Energy policy, Research and Development, Deployment subsidies

\section{Introduction}

Climate and energy policies need to address at least two well-known market failures (1). Without a direct price on negative externalities such as $\mathrm{CO}_{2}$ emissions, welfare losses will persist because economic agents lack incentives to invest in $\mathrm{CO}_{2}$ abatement. In addition, private companies tend to underinvest in low carbon energy R\&D. For both market failures, economists often advocate appropriate government interventions such as carbon pricing and comprehensive public R\&D programs. This is essential in successful technological innovation frameworks, based on synergistic packages of technology-push and demand-pull measures (2) (3) (4) (5) (6). The high deployment cost of renewable technologies - especially of PV attracts more and more attention in the largest European economies (7), also, RD\&D efforts are generally considered to be insufficient (8) (9). We argue that the debate on the optimal deployment trajectory for renewables should explicitly consider the balance between deployment incentives and $R \& D$ support. This paper aims to provide insight in the balance between wind and PV deployment and R\&D efforts in Europe.

\section{Methodology}

\subsection{Expected growth in wind and PV electricity production}

In order to estimate future costs we used two conservative scenarios (a moderate scenario and a policy driven scenario) on wind and PV electricity production up until 2020. These scenarios are based on reports by the European Photovoltaic Industry Association (EPIA) (10) and Tradewind (11) (Appendix, table 1-A). In the latter report we found projections of wind capacity growth (MW) which we then multiplied with full load hour data (FLH; [MWh/MW/y]) to estimate yearly wind electricity production. FLH data were calculated based on real production data for 2007 and 2008 by Eurobserv'er (12). We would like to point out that our FLH assumptions based on Eurobserv'er data are slightly lower than those based on EWEA (European Wind Energy Association) data (13). With respect to PV, the data on installed capacity (10) was multiplied with data on the yearly energy output [kWh/kWp/y] 
obtained from PV-GIS Europe (Photovoltaic Geographical Information System) (14) to obtain estimates of total annual PV electricity production.

\subsection{Current and future deployment costs}

Current deployment costs in Euro/MWh are based on data by the European Renewable Energies Federation (EREF) (15). To estimate the further evolution of deployment costs, we follow the IEA (16) and assume that support schemes will be gradually phased out by 2020 . Thus, we assume that PV-systems or wind turbines installed after December $31^{\text {st }} 2019$ no longer receive subsidies. For PV this assumption is a challenge, on-shore wind however is already competitive under optimal conditions. We are fully aware that the fading out of support schemes should not necessarily become a reality. This assumption however keeps the total deployment costs within a reasonable range. As a result, our calculations of the total deployment costs should be interpreted as very conservative. Based on existing schemes of Green Certificates or Feed-in Tariffs, the average production subsidies in the EU for PV and wind are estimated at respectively $326 € / \mathrm{MWh}$ and $56 € / \mathrm{MWh}$ in 2010. In practice, deployment subsidies vary significantly across Member States (15). We assumed that these support levels will decline steadily to be phased out by 2020 (Figure 1).

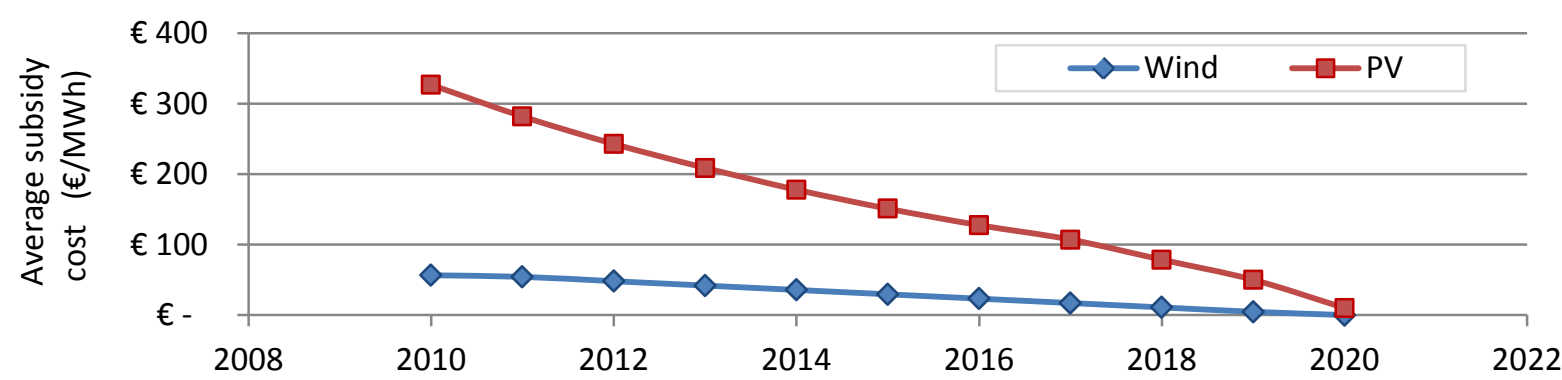

Fig. 1: Decline of average subsidies ( $€ / M W h)$ for $P V$ and wind electricity in the EU (based on(15))

In order to obtain total PV and wind deployment costs for each EU Member State, the estimated electricity production in a given year was multiplied with the corresponding production subsidy. In most countries the subsidies for PV electricity are guaranteed for 20-25 years, starting when the first MWh of electricity is produced. In this paper, a support period of 20 years was assumed for PV. Wind subsidies were assumed to be guaranteed for only 15 years. Note that these conservative assumptions on the duration of the guaranteed support have a huge impact on the total cumulative cost.

\subsection{Research, development and demonstration}

Public RD\&D investment data from EU Member States were retrieved from the IEA RD\&D database (17). Missing data from 2009 or 2008 were replaced by the most recent data available for a given Member State. For the alternative $R \& D$ scenario, $R \& D /$ sales ratios for $\mathrm{PV}$ and wind technology companies are compared to relevant benchmark values in competitive engineering sectors. As PV and wind technology companies have low R\&D/sales ratios, an R\&D-investment gap based on projected total sales for both technologies and the $7 \% \mathrm{R} \& \mathrm{D} /$ sales benchmark of engineering sectors was calculated. As a matter of reference, we compare our investment gap estimates to investment needs obtained from recent IEA reports (8) (9). The methodology of the IEA is however fundamentally different since it uses a partial equilibrium model to find the cost-effective technology portfolios to halve global emissions by 2050 . Nevertheless we believe it to be a good reference point in this framework. 


\section{Results and Discussion}

\subsection{Expected growth in wind and PV electricity production}

From our conservative scenarios we find that, by 2020, 102-159 TWh is estimated to be produced by PV-systems and 311-399 TWh by wind turbines, in the EU-27. Table 1 shows that our estimates of future electricity production are quite conservative when compared to the standard scenarios from EREC (18), EPIA (19), EWEA (13) and the EU (20). We opted for this approach to ensure that the cost estimates resulting from our scenarios (see below) are within reasonable range. Furthermore, the wide range of projections given in Table 1 illustrate that estimating future electricity production comes with great uncertainty.

Table 1: Estimated wind and PV electricity production and share in total demand in the EU by 2020

\begin{tabular}{llccccc}
\hline \multicolumn{2}{l}{ Technology } & This Paper & EPIA (19) & EWEA (13) & EREC (18) & EU (20) \\
\hline PV & Prod (TWh) & $102-159$ & $140-420$ & & 180 & \\
& Share (\%) & $2.7-4.2$ & $3.7-11.1$ & & 4.7 & \\
\hline \multirow{2}{*}{ Wind } & Prod (TWh) & $311-399$ & & $580-681$ & 477 & $399-525$ \\
& Share (\%) & $8.2-10.5$ & & $15.3-17.9$ & 12.6 & $10.5-13.8$ \\
\hline
\end{tabular}

Sources: (13) (20) (18) and (19); total electricity demand in 2020 is estimated to be 3795 TWh (20)

\subsection{Current and future deployment costs}

Figure 2 shows the evolution of annual and cumulative PV and wind electricity subsidy costs in the EU-27 from 2007 until 2040 in a moderate (Mod) and a policy driven (PD) scenario. It is clear that PV subsidy costs will be much higher than wind subsidy costs, and (given the above mentioned assumptions) also last for a longer period. We find that annual subsidy costs for PV in the period 2020-2026 will be $€ 18-26$ Bio. Annual wind subsidy costs will rise up to $€$ 6-9 Bio by 2020 and fade out by 2034. Total annual subsidy costs (PV + wind) will probably peak in 2020 and, depending on the scenario, could amount to $€ 25-35$ Bio in that year. The total nominal cumulative cost of wind and PV subsidies are estimated to reach around $€$ 471-661 Bio by 2040 for the whole of the EU-27.
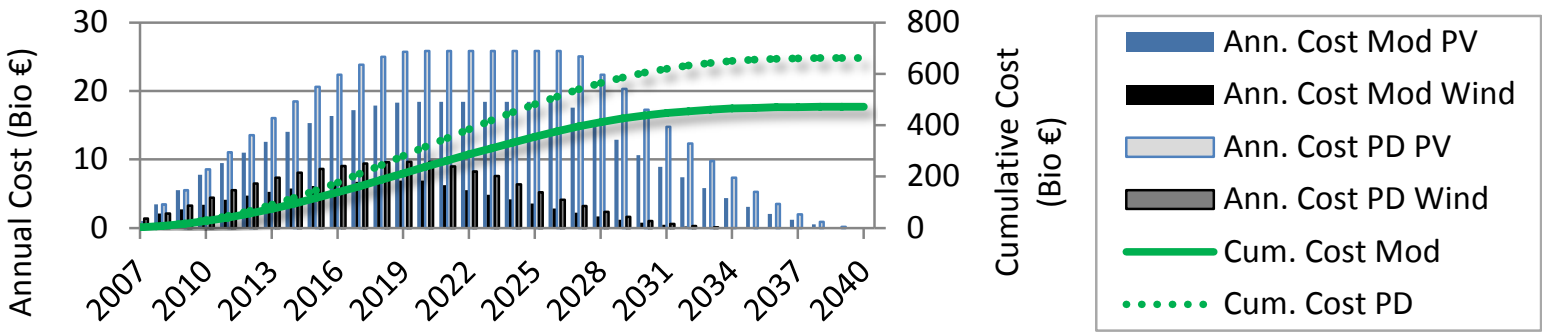

Fig. 2: Annual and cumulative deployment costs for PV and wind (based on (10), (11) and (15))

Table 2 illustrates that in 2020 the total average annual deployment cost per person (ADCPP) in Germany could reach $€ 156$ in the policy driven scenario. These high costs are caused mainly by the high PV FIT's granted in Germany in the period 2007-2010, resulting in annual costs of $€$ 4-5 Bio by 2010 already. By 2020, annual PV deployment costs in Germany are estimated at $€$ 9-11 Bio, which is almost 50\% of the total of EU-27 PV subsidy costs, and more than total annual wind subsidy costs for the whole of the EU. The data in Table 2 also indicates that countries that rely more on wind energy and invest little in PV will have fewer problems facing the subsidy costs. To illustrate this we compare the U.K. and the Czech Republic. Both are estimated to have a similar combined share of wind and PV in total electricity supply by 2020 (Wind and PV together account for 6-9\% of total supply). The U.K. 
will reach this primarily through the deployment of wind energy (wind shares of 5.2-8.5\%), the Czech Republic, on the other hand will invest heavily in PV. Table 2 shows that this has major consequences for electricity consumers, with ADCPP by 2020 for the Czech electricity consumer of 72-115 €, compared to only 13-22 € for the U.K. consumer.

Table 2: Average annual deployment cost per person (ADCPP) across member states in the year 2020

\begin{tabular}{llrrrrrrrrrr}
\hline \multicolumn{2}{c}{ ADCPP $(€)$} & DE & EL & CZ & BE & ES & IT & PT & BU & FR & UK \\
\hline PV & Mod & 105 & 36 & 71 & 48 & 76 & 43 & 22 & 18 & 16 & 4 \\
$(€)$ & PD & 132 & 91 & 121 & 56 & 92 & 62 & 47 & 44 & 28 & 7 \\
\hline Wind & Mod & 18 & 11 & 2 & 12 & 22 & 18 & 45 & 3 & 15 & 10 \\
$(€)$ & PD & 24 & 18 & 7 & 19 & 27 & 25 & 48 & 4 & 20 & 15 \\
\hline Total & Mod & 123 & 46 & 72 & 60 & 98 & 61 & 67 & 21 & 31 & 13 \\
$(€)$ & PD & 156 & 109 & 128 & 75 & 119 & 88 & 94 & 48 & 48 & 22 \\
\hline PV/wind & Mod & 5,95 & 3,30 & 42,61 & 3,91 & 3,54 & 2,44 & 0,49 & 6,91 & 1,05 & 0,41 \\
& PD & 5,56 & 5,18 & 16,46 & 2,92 & 3,39 & 2,44 & 0,97 & 10,9 & 1,38 & 0,48 \\
\hline
\end{tabular}

(Based on data from (10), (11) and (15))

These figures do not reflect the net-cost for society since the production of renewable electricity avoids the production of fossil or nuclear electricity. More intermittent renewable electricity production will however imply significant additional grid investments. It is at this stage very speculative to derive the net-cost from the deployment cost between now and 2040 . We can nevertheless assume that the cost increase to the average electricity consumer will be significant. Keep in mind that our calculations are restricted to PV and wind while most countries have regimes to support other renewable energy technologies as well. Adding for instance biomass or geothermal FIT's will further increase these costs.

\subsection{Investments in Research, Development and Demonstration}

\subsection{1. $R D \& D$ needs according to the IEA}

The IEA (8) (9) (17) claims that global annual public RD\&D budgets for wind and solar (PV + concentrated solar power + solar boilers) should be around USD 1800-3600 Mio, which is about a fivefold increase compared to current PV public RD\&D investments and a tenfold increase in wind public RD\&D. In line with these recommendations, we assume that current public RD\&D budgets in the EU-27 should be 5 times higher in the case of PV and 10 times higher in the case wind. Given current EU-27 RD\&D budgets for wind and PV of respectively $€ 136$ Mio and $€ 184$ Mio, the above mentioned assumption resulted in estimated annual RD\&D needs for wind and PV in the EU-27 of $€ 1360$ Mio and $€ 920$ Mio respectively.

\subsubsection{Estimating optimal $R \& D$ expenditures}

It is difficult to define the optimal R\&D efforts for PV and wind technologies since these sectors are still in transformation and operate in an artificially protected and fully subsidized environment with production targets up to 2020. If the sectors would collectively agree not to innovate, they can continue to sell current technologies. Nemet (3), for example, has pointed out that demand-pull measures might negatively impact non-incremental technological change. In general, manufacturing firms in Korea and Canada spend about 5-6\% of their turnover on R\&D (21). Major consumer electronics firms that operate in competitive markets like Siemens, Samsung, Nokia, Sony and Robert Bosch spend about 6-10\% of their sales on $\mathrm{R} \& \mathrm{D}$ (22). Based on the annual reports of the major international PV and wind companies however, we find that these companies invest on average only $2 \%$ of their sales in R\&D. As 
renewable energy companies are less $R \& D$-intensive compared to comparable mature industries, we have strong indications of private underinvestment in renewable energy R\&D.

To quantify this investment gap, we assume that the PV and wind industry should invest at least $7 \%$ of sales in $R \& D$ to replicate the average innovation dynamics of the engineering sectors. For this purpose we estimated total sales in the wind and PV sector between now and 2020. This was achieved by multiplying annual installed capacities with the cost per Watt. We assumed that wind energy investment costs would decline from $1.3 € / \mathrm{W}$ in 2005 to $1 € / \mathrm{W}$ in 2020. For PV we assumed a decline from $4 € / \mathrm{Wp}$ in 2007 to $3.5 € / \mathrm{Wp}$ in 2010 and $2 € / \mathrm{Wp}$ in 2020 (cost estimates based on (11), (23), (24) and (25)). This resulted in fairly constant annual sales in the wind and PV industry between 2010 and 2020 (Fig. 3). Sales in wind are about 9 Bio/y in a moderate scenario and 14 Bio/y in a policy driven scenario. PV sales are higher, reaching around $30 \mathrm{Bio} / \mathrm{y}$ in a policy driven scenario and $18 \mathrm{Bio} / \mathrm{y}$ in a moderate scenario. If the public sector were to support the industry by funding R\&D to obtain the $7 \%$ ratio, they would have to spend a complementary amount equal to $5 \%$ of sales ( $7 \%$ in total minus $2 \%$ private). Using this method we obtained " $5 \%$ of sales" R\&D estimates, which are much higher than current public RD\&D investments in PV and wind (Table 3).

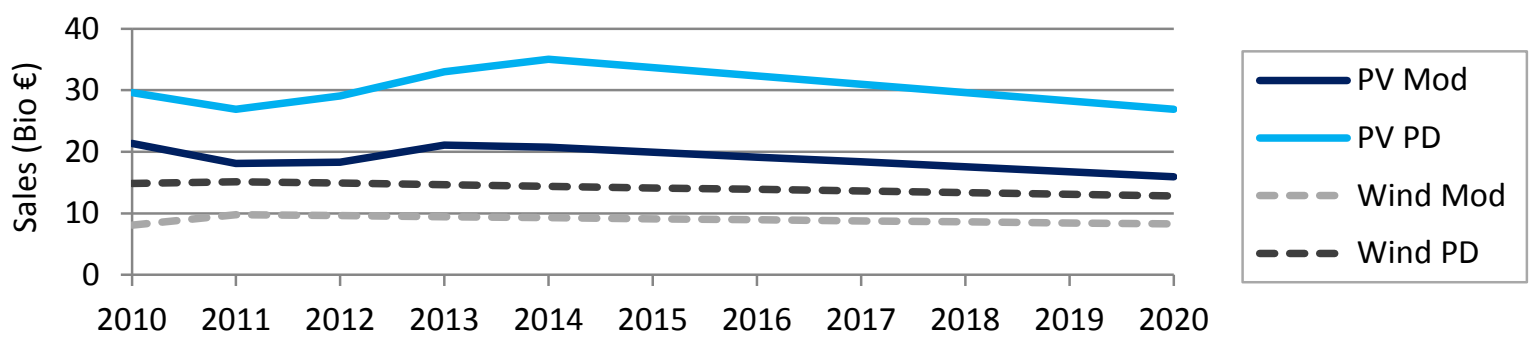

Fig. 3: Estimated annual sales for PV and wind in the EU-27 (based on (10) (11) (23) (24) \& (25))

Table 3: Annual R\&D gap as 5\% of sales in the EU in the period 2010-2020

\begin{tabular}{lrrrrr}
\hline $\begin{array}{r}\text { Current EU public RD\&D } \\
(€ \text { Mio) }\end{array}$ & $\begin{array}{r}\text { Annual sales } \\
(€ \text { Mio) }\end{array}$ & $\begin{array}{r}\text { R\&D gap as 5\% of sales } \\
(€ \text { Mio) }\end{array}$ \\
\hline PV & & Mod & PD & Mod & PD \\
Wind & 184 & 18000 & 30000 & 900 & 1500 \\
\hline
\end{tabular}

(Based on data from (17) and annual reports from the solar and wind industry)

\subsection{Balancing push and pull measures}

\subsubsection{Results}

EU Member States have invested - and are likely to continue to invest - huge sums in demand-pull measures to stimulate the deployment of renewable technologies like PV and wind. When comparing these high costs to the low investments in RD\&D supply-push measures, it appears that the budgets are not in balance. To obtain better insight in the imbalance between demand-pull and supply-push measures, we calculated a pull/push ratio under difference scenarios. Table 4 shows that the pull/push ratio would increase from 35-41 today to about $79-111$ by 2020 if current RD\&D budgets were to remain unchanged (baseline scenario). Such that by 2020, in a policy driven scenario, for every euro going to wind or PV RD\&D, there are 111 euro's going to deployment subsidies. Wind and PV industries currently invest on average $2 \%$ of sales in R\&D. Therefore, we believe that governments could support the industry by investing an amount equal to $5 \%$ of annual sales, such that a $7 \%$ sales/R\&D ratio - common in engineering and electronics industry - would be achieved. This would result 
in a significant decrease of the pull/push ratio from 35-41 (Baseline scenario) to 6-8 ("5\% of sales" scenario) in 2010. Since in the " $5 \%$ of sales" scenario R\&D budgets evolve in line with annual sales, pull/push ratios are more flexible to changing market circumstances. Notice for example that the " $5 \%$ of sales" pull/push ratio does not differ that much when comparing wind and PV, this in contrast to the other scenarios. The estimates of needed RD\&D investments based on IEA suggestions result in pull/push ratios that are quite similar to the " $5 \%$ of sales" ratio. However, the differences between the pull/push ratio for wind and PV are much bigger. Despite this fact, we are convinced that following the IEA's advice would certainly be a step in the right direction.

Table 4: Comparison of Push and Pull measures for wind and PV in the EU in 2010 and 2020

\begin{tabular}{llrrrrrr}
\hline & & \multicolumn{2}{c}{$\begin{array}{c}\text { PV } \\
\text { (€ Bio/year) }\end{array}$} & \multicolumn{2}{c}{$\begin{array}{c}\text { Wind } \\
(€ \text { Bio/year) }\end{array}$} & \multicolumn{2}{c}{ Total } \\
& & Mod & PD & Mod & PD & Mod & PD \\
\hline Push & Baseline & 0.184 & 0.184 & 0.136 & 0.136 & 0.32 & 0.32 \\
& R\&D 5\% of annual sales & 0.90 & 1.50 & 0.45 & 0.70 & 1.35 & 2.20 \\
& IEA Annual RD\&D needs & 0.92 & 0.92 & 1.36 & 1.36 & 2.28 & 2.28 \\
\hline Pull & 2010 & 7.77 & 8.57 & 3.37 & 4.43 & 11.1 & 13.0 \\
& 2020 & 18.4 & 25.6 & 6.95 & 9.67 & 25.4 & 35.5 \\
\hline Pull & Push & \multicolumn{1}{c}{ pull/push } & pull/push & pull/push \\
\hline 2010 & Baseline & 42 & 47 & 25 & 33 & 35 & 41 \\
& R\&D 5\% of annual sales & 9 & 6 & 7 & 6 & 8 & 6 \\
& IEA Annual RD\&D needs & 8 & 9 & 2 & 3 & 5 & 6 \\
\hline 2020 & Baseline & 100 & 141 & 51 & 71 & 79 & 111 \\
& R\&D 5\% of annual sales & 20 & 17 & 15 & 14 & 19 & 16 \\
& IEA Annual RD\&D needs & 20 & 28 & 5 & 7 & 11 & 16 \\
\hline
\end{tabular}

(Based on (8), (9), (10), (11), (15), (17) and annual reports of solar and wind companies)

\subsubsection{Sensitivity analysis and remarks}

Many authors agree that governments should invest more in renewable R\&D; however the "optimal" amount of R\&D efforts is difficult to estimate. Fischer and Newell (26) search for optimal R\&D subsidy levels using a theoretical model that optimizes renewable policies. They find that the optimal R\&D subsidy should be equal to $6 \%$, which is remarkably close to our empirically estimated value of $5 \%$. Furthermore, the optimal public R\&D estimates by the IEA are also quite comparable to our estimates. From this we can conclude that our estimated " $5 \%$ of sales" public RD\&D budget is in line with recent findings. Nevertheless, it is interesting to evaluate the effect of the " $5 \%$ of sales" assumption on the overall results. Table 5 shows that adapting this assumption does have significant effects on the pull/push ratio. However, even the very conservative estimate of $2.5 \%$ results in pull push ratios that are smaller than currently found in the EU (namely 25-33 for wind and 42-47 for PV). The ratios rise by 2020 due to rising deployment costs, however not as dramatic as compared to the status quo scenario (see Table 4).

When interpreting these results one should keep in mind that, throughout this paper, we have always opted for the more conservative approach. For example, the growth of wind and PV electricity production is assumed to be moderate compared to other scenario's (see Table 1). Also, the assumption that subsidies will gradually fade out by 2020 is a tentative one. To our knowledge, only a few governments have presented such decreasing policy schemes (for example Greece (15) and the region of Flanders). It remains to be seen whether or not this practice becomes widespread in Europe. Governments that do not reduce renewables support 
over time will experience higher costs than the estimates mentioned above. If PV and wind electricity production were to grow at rates mentioned by the EWEA's 'high' scenario (13) or the EPIA's 'paradigm shift' scenario (19) costs will be much higher, resulting in even higher burdens on electricity consumers.

Table 5: Pull Push ratio under different assumptions on optimal public R\&D budgets

\begin{tabular}{|c|c|c|c|c|c|c|c|}
\hline $\begin{array}{l}\text { Pull/Push } \\
\text { year }\end{array}$ & R\&D/Sales ratio & $\begin{array}{l}\text { PV } \\
\text { Mod }\end{array}$ & PD & $\begin{array}{l}\text { Wind } \\
\text { Mod }\end{array}$ & $\mathrm{PD}$ & $\begin{array}{l}\text { Total } \\
\text { Mod }\end{array}$ & $\mathrm{PD}$ \\
\hline \multirow[t]{2}{*}{2010} & $2.5 \%$ of annual sales & 17 & 11 & 15 & 13 & 17 & 12 \\
\hline & $7.5 \%$ of annual sales & 6 & 4 & 5 & 4 & 6 & 4 \\
\hline \multirow[t]{2}{*}{2020} & $2.5 \%$ of annual sales & 41 & 34 & 31 & 28 & 38 & 32 \\
\hline & $7.5 \%$ of annual sales & 14 & 11 & 10 & 9 & 13 & 11 \\
\hline
\end{tabular}

\section{Conclusion}

Despite the uncertainties surrounding the mechanisms behind technology support measures, it seems that a pull/push ratio of 40 , estimated here, does not seem optimal. This ratio could increase up to 79-111 by 2020 if current policies were to remain in place. Overall, we can safely say that European governments should critically evaluate current renewables subsidy schemes, especially for PV systems, and raise public RD\&D investments. These higher RD\&D budgets could drive down production costs, which will result in a decreasing need for demand-pull measures in the longer run. Further efforts should be made to obtain more reliable and complete data on public and private RD\&D expenditure and to improve our understanding on the interactions between demand-pull and supply-push policy measures, such that policy makers have the knowledge and the tools to bring new, promising technologies to the market in an effective and efficient manner.

\section{References}

[1] R. G. Newell, The role of markets and policies in delivering innovation for climate change mitigation, Oxford Review of Economic Policy 26, 2010, pp. 253-269.

[2] V. Norberg-Bohm, The role of government in energy technology innovation: insights for government policy in the energy sector, Harvard University, Belfer Center for Science and International Affairs, 2002.

[3] G. F. Nemet, Demand-pull, technology-push, and government-led incentives for nonincremental technical change, Research Policy 38, 2009, pp. 700-709.

[4] T. Jamasb, W. J. Nuttal, and M. Pollit, The case for a new energy research, development and promotion policy for the UK, Energy Policy 36, 2008, pp. 4610-4614.

[5] P. H. Kobos, J. D. Erickson and T. E. Drennen, Technological learning and renewable energy costs: implications for US renewable energy policy, Energy Policy 34, 2006, pp. 1645-1658.

[6] G. F. Nemet and E. Baker, Demand subsidies versus R\&D: Comparing the uncertain impacts of policy on a pre-commercial low-carbon energy technology, The Energy Journal 30, 2009, pp. 49-80.

[7] M. Frondel, N. Ritter and C. M. Schmidt, Germany’s solar cell promotion: Dark clouds on the horizon, Energy Policy 36, 2008, pp. 4198-4204.

[8] IEA, Global gaps in clean energy R\&D, International Energy Agency, 2010. 
[9] IEA, Global gaps in clean energy research, development and demonstration, International Energy Agency, 2009.

[10] EPIA, Global Market outlook for photovoltaics until 2014, European Photovoltaic Industry Association, 2010.

[11] Tradewind, Integrating Wind, 2009.

[12] Eurobserv'er, State of renewable energy in Europe, 2009.

[13] EWEA, Pure power, wind energy targets up to 2020 and 2030, 2009.

[14] M. Šúri, T. A. Huld, E. D. Dunlop and H. A. Ossenbrink, Potential of solar electricity generation in the European Union member states and candidate countries, Solar Energy 81, 2007, pp. 1295-1305.

[15]EREF, Prices of renewable energies in Europe, European Renewable Energies Federation, 2009.

[16] IEA, Energy Technology Perspectives 2010, International Energy Agency, 2010.

[17] IEA, RD\&D statistics [accessed 28 October 2010] <http://www.iea.org/stats/rd.asp.>

[18] European Commission, EU energy trends to 2030, 2010.

[19] EREC, RE-thinking 2050, European Renewable Energy Council, 2010.

[20] EPIA, Set for 2020, European Photovoltaic Industry Association, 2010.

[21] OECD, Measuring Innovation: a new perspective, 2010.

[22] National Science Board, Science and engineering indicators 2010, 2010. [accessed 25 November 2010] <http://www.nsf.gov/statistics/seind10/c/cs1.htm.>

[23]EWEA, Wind energy the facts, 2010. [accessed 5 December 2010] <http://www.windenergy-the-facts.org/documents/download/Chapter3.pdf.>

[24]EPIA, Solar Generation 6, 2010. [accessed 25 November 2010] <http://www.epia.org/publications/epia-publications.html.>

[25] IEA, Technology Roadmap: Solar Photovoltaic Technology, 2010. [accessed 5 December 2010] <http://www.iea.org/papers/2010/pv_roadmap.pdf.>

[26]R.G. Newell and C. Fischer, Environmental and technology policies for climate mitigation, Journal of Environmental Economics and Management 55, 2008, pp. 142-162 